\title{
Perspective
}

PERSPECTIVE Actualité en histoire de l'art

Comptes rendus | 2010

Lucas Burkart éd. et al., Le Trésor au Moyen Âge :

discours, pratiques et objets, (Micrologus' Library, 32), Florence, Sismel, 2010

\section{Anne-Orange Poilpré}

\section{OpenEdition}

1 Journals

Édition électronique

URL : http://journals.openedition.org/perspective/2461

DOI : $10.4000 /$ perspective. 2461

ISSN : 2269-7721

Éditeur

Institut national d'histoire de l'art

Référence électronique

Anne-Orange Poilpré, « Lucas Burkart éd. et al., Le Trésor au Moyen Âge : discours, pratiques et objets,

(Micrologus' Library, 32), Florence, Sismel, 2010 », Perspective [En ligne], Comptes rendus, mis en ligne le 30 juillet 2013, consulté le 01 octobre 2020. URL : http://journals.openedition.org/perspective/2461 ; DOI : https://doi.org/10.4000/perspective.2461

Ce document a été généré automatiquement le 1 octobre 2020. 
Lucas Burkart éd. et al., Le Trésor au Moyen Âge : discours, pratiques et objets, (Micrologus' Library, 32), Florence, Sismel, 2010

Anne-Orange Poilpré

\section{RÉFÉRENCE}

Lucas Burkart éd. et al., Le Trésor au Moyen Âge : discours, pratiques et objets, (Micrologus' Library, 32), Florence, Sismel, 2010. 
1 Au cœur de nombreux travaux d'histoire de l'art médiéval récents (voir à ce sujet Michele Tomasi, «Des trésors au Moyen Âge : enjeux et pratiques, entre réalités et imaginaire ", dans Perspective, 2009-1, p. 137-141), la thématique du trésor donne aux études sur les arts précieux du Moyen Âge une vitalité nouvelle lorsqu'elle contribue à ouvrir le débat vers d'autres disciplines que l'histoire de l'art. Si le terme caractérise depuis longtemps des travaux monographiques sur des trésors ecclésiastiques spécifiques, il tend aujourd'hui à mieux refléter une catégorie complexe de la pensée et de la pratique médiévale. C'est ce qu'entendent mettre en lumière les actes de ce colloque, tenu à Bâle et à Neuchâtel en 2006, dans le sillage d'un premier ouvrage collectif paru en 2005 dirigé par les mêmes auteurs: Le Trésor au Moyen Âge: questions et perspectives de recherches, Neuchâtel, 2005. Les contributions de cette deuxième publication sont articulées en trois thèmes : discours, pratiques et objets. Le premier examine le sens des termes littéraires désignant le trésor et mettant en lumière la complexité de cette notion, qui relève aussi bien du concret que de la métaphore spirituelle. Le second volet donne corps à la pratique des objets de trésor, concrétisée par la liturgie et le rituel chrétien en général, mais aussi par le don et l'échange. La troisième partie se penche sur les objets eux-mêmes, leur caractère cumulatif, et leur capacité à articuler un échange spirituel avec l'au-delà, dépassant par là une richesse et une matérialité a priori contraires au dénuement et à l'humilité exigés pour l'accès au salut chrétien. La richesse de cet ouvrage collectif montre bien la fécondité de cette notion pour penser les arts religieux au Moyen Âge, et on entrevoit son intérêt pour l'étude des manuscrits et de leurs reliures précieuses, qui gagneraient à trouver une place dans le cadre de cette réflexion, comme cela avait été esquissé par Eric Palazzo dans « Le livre dans les trésors du Moyen Âge. Contribution à l'histoire de la memoria médiévale », Annales ESC, n52-1, 1997, p. 93-118. 